\title{
O ENSINO DE HISTÓRIA NAS SÉRIES INICIAIS DO ENSINO FUNDAMENTAL: A APROPRIAÇÃO DO LIVRO DIDÁTICO
}

\author{
THE TEACHING OF HISTORY IN THE SERIES OF EARLY ELEMENTARY \\ SCHOOL: A TEXTBOOK OF OWNERSHIP
}

Susana Barbosa Ribeiro Bernardo ${ }^{1}$

\begin{abstract}
RESUMO: O presente artigo objetiva participar do debate acerca do ensino de história, problematizando as práticas e os saberes de docentes e de discentes dos anos iniciais do Ensino Fundamental, a partir das apropriações que estes fazem dos livros didáticos de história. Empreende técnicas da pesquisa etnográfica, perspectivando cotejar os saberes de formação dos docentes e, no campo do ensino da história, os saberes ensinados e os saberes apreendidos.
\end{abstract}

Palavras-Chave: Ensino de história. Formação docente. Saberes históricos. Livro didático.

\begin{abstract}
This paper aims to contribute to the debate about the teaching of history, questioning the practices and knowledge of teachers and students of the early years of elementary school, from appropriations of these make history textbooks. Undertake ethnographic research techniques, looking ahead to compare the knowledge and training of teachers in the field of history teaching, the knowledge taught and the knowledge learned.
\end{abstract}

KEYWORDS: Teaching history. Teacher Training. Historical knowledge. Textbook.

\footnotetext{
${ }^{1}$ Mestre em História pela Universidade Estadual de Londrina (UEL) na linha de Pesquisa História \& Ensino.
} 


\section{Introdução}

Aumenta a quantidade de produtos culturais midiáticos, como revistas e fascículos comercializados em bancas de jornal, DVDs, CD-Roms, sites que tratam dos mais variados temas históricos. Filmes, jogos eletrônicos, quadrinhas e literatura (adulta, infantil e juvenil), recorrem a elementos históricos para produzir suas narrativas. Contraditoriamente, enquanto tais materiais parecem interessar o grande público, a História como disciplina escolar parece permanecer em sua "tradição" de ser entendida como "aborrecida", ultrapassada e sem sentido.

O presente artigo designa participar do debate em curso acerca do ensino de história, situando-se na discussão sobre as práticas e representações de docentes e discentes do Ensino Fundamental (do 10 ao $40 \mathrm{ano}^{2}$ ), que no Brasil corresponde ao ensino de crianças de 7 a 10 anos. A pesquisa desenvolveu-se segundo preceitos postos por ANDRÉ (1995), por meio de contato direto do pesquisador com o "objeto" de pesquisa e utilização de técnicas de observação próximas ao tipo etnográfico, entrevistas intensivas e questionários. Buscou-se analisar os saberes que os professores acionam para ensinar história e quais saberes que os alunos produzem em relação à história, sob a mediação do livro didático. Para isso, recorreu-se nesta pesquisa a um grupo de professores e alunos da Escola Municipal de Ensino Fundamental e Infantil "José Ozório de Oliveira", localizada no centro da cidade de Tarumã, interior do Estado de São Paulo ${ }^{3}$, onde se acompanhou/observou as aulas de oito professores das séries iniciais do Ensino Fundamental, bem como a forma que utilizavam o livro didático de História. Em relação aos alunos, aplicou-se questionário visando obter informações sobre seu entendimento quanto à história como disciplina

\footnotetext{
${ }^{2} \mathrm{Na}$ nova nomenclatura, do $1^{\circ}$ ao $5^{\circ}$ ano. Fundamentado na Lei no 11.114 , de $16 / 5 / 2005$, Lei no 11.274, de 06/2/2006, Resolução CNE/CEB n03, de 03/8/2005, Parecer CNE/CEB no 18, de 15/9/2005 e Deliberação CEE no 299, de 03/10/2006, o Ensino Fundamental passa a ter 9 anos, a partir de 2007. Portanto, consideramos aqui apenas as primeiras 4 séries do Ensino Fundamental.

${ }^{3}$ Entende-se que tomar um grupo situado como sujeito de pesquisa não constitui um "estudo de caso", pois embora haja diferenças significativas nas práticas e representações dos agentes escolares, conforme, por exemplo, a situação econômica da realidade em que a escola está inserida, existem várias equivalências já apontadas por aqueles que focalizam a educação histórica, como Peter Lee na Inglaterra, Isabel Barca em Portugal e Maria Auxiliadora Schmidt no Brasil.
} 
escolar e quanto ao livro didático de história, entendendo que o modo de que o aluno se apropria do livro didático termina por (também) revelar as práticas docentes. Ao todo, 195 alunos participaram da entrevista, sendo 19 alunos do $1^{\circ}$ ano, 53 alunos do $2^{\circ}$ ano, 46 alunos do $3^{\circ}$ ano e 77 alunos do $4^{0}$ ano.

Ressalta-se que a formação do professor das quatro primeiras séries iniciais ocorre nos cursos de pedagogia, por isso são denominados de professores "generalistas". Dos que ministram aulas nesta série, são poucos os professores que fizeram licenciatura em áreas específicas do conhecimento (os chamados "especialistas"). A partir da $5^{a}$ série, os professores devem ser formados em áreas específicas, ou seja, a disciplina de história deve ser ministrada na escola por licenciados neste curso. Em razão do exposto, levantaram-se algumas questões: Como esses professores, os "generalistas" consideram a disciplina escolar de história? Quais as concepções e práticas do professor não formado exclusivamente em história? Como os professores lidam com o livro didático de história? $E_{\text {, }}$ ainda, em relação aos alunos: O que entendem por história? O que consideram sobre as aulas de história? O livro didático interfere, auxilia, complementa ou não chega a ser importante na construção do saber histórico escolar? Quais elementos vinculados ao modo do aluno apropriarse do livro didático permite entrever as práticas docentes?

Além da problematização sobre os aspectos internos do livro didático - que são de certo, pertinentes -, são escassas as análises sobre como esses materiais são apropriados no cotidiano escolar. Existem sim, muitas críticas à "dependência" do professor em relação ao livro didático e/ou ao ensino "tradicional" de história, porém, não muitas pesquisas voltadas para descobrir o que poderia ajudar a explicar esse quadro.

\section{Os Saberes Históricos do Professor "Generalista"}

O período de observação no campo de pesquisa (de oito meses) foi acompanhado por uma resistência velada por parte dos docentes, os quais de uma forma geral procuraram restringir as visitas da pesquisadora. 
Durante o acompanhamento dessas aulas, os docentes "generalistas" apresentaram-se deveras preocupados e constrangidos por serem observados por uma "especialista" em história, chegando por vezes, a solicitar à pesquisadora para acrescentar ou confirmar informações em sala de aula, tendo em vista sua insegurança ante ao conteúdo ministrado. Este comportamento por parte dos professores justifica-se por não possuírem formação específica em história e por se sentirem "avaliados", o que provavelmente fez com que supusessem ocupar um "lugar de poder" diferente e inferior em relação ao pesquisador. Segundo Bourdieu, esse desnível entre pesquisado e pesquisador ocorre porque "o pesquisador ocupa uma posição superior ao pesquisado na hierarquia das diferentes espécies de capital, especialmente de capital cultural" (1997, p. 695).

No decorrer das aulas, constatou-se que os professores das quatro séries iniciais conheciam o universo sociocultural específico de seus educandos, a maneira de falar, os valores, os comportamentos e as aspirações de seus alunos, favorecendo a comunicação e a prática pedagógica. A permanência de aproximadamente cinco horas diárias com os educandos certamente cria laços afetivos beneficiando o processo de ensino-aprendizagem, mas deve-se lembrar de que essa competência em lidar com os alunos também é fornecida pelos cursos de formação de professores, nos quais se enfatizam as ciências da pedagogia e da didática. Contudo, embora não seja o foco investigativo desta pesquisa, infere-se que nada pode garantir que os professores de história, responsáveis pelo $5^{0}$ ano em diante, portanto, licenciados neste curso, tenham práticas e concepções diferentes dos professores formados em pedagogia e não em história. Apenas por hipótese, pode-se dizer que o professor "especialista" apresenta maior domínio dos conteúdos e/ou saberes históricos em comparação com o professor "generalista", e que este, por sua vez, tenha maior domínio dos saberes pedagógicos, se comparado ao professor "especialista".

A tendência dos professores "generalistas", observada na seleção que realizaram do livro didático é de valorizar as áreas de português (letramento) e matemática em detrimento das outras disciplinas. Existe um 
equívoco, não só por parte dos destes professores, mas principalmente nos meios acadêmicos, em acreditar que os conhecimentos históricos não são adequados à aprendizagem das crianças desta faixa etária, pois estas não teriam capacidade cognitiva de "abstração", de pensar um passado que não viveram, como se em português e matemática não demandasse igualmente este tipo de capacidade (CARRETERO, 1997). Também é característica dos tempos atuais, ver mais "utilidade" em português e matemática para a formação do trabalhador capaz de dar conta da produtividade no novo mundo do trabalho (BITTENCOURT, 2004).

Em história, pelo menos no que diz respeito ao observado nos sujeitos da pesquisa, o que mais chamou a atenção foi o fato de que a informação costuma ser tratada como conhecimento. Sem que a informação seja devidamente organizada, sistematizada, re(elaborada) e contextualizada, não se criam condições para desenvolver o entendimento dos conceitos, processos, temporalidades, enfim, dos componentes-chave desta disciplina escolar. A escola em questão tem Internet disponível a todos, porém, em uma das aulas observadas, a professora propôs uma pesquisa aos alunos do $4^{\circ}$ ano a respeito dos imigrantes vindos ao final do século XIX ao Brasil, os quais foram realizá-la no laboratório de informática. Com muita habilidade técnica os estudantes procuraram na Internet o tema solicitado e assim que o encontravam, tratavam de copiá-lo em seu caderno, sem ter realizado primeiro uma leitura integral do texto, ou ainda, sem compará-lo com outros possíveis textos disponíveis ou interpretá-lo. Em aula ${ }^{4}$, percebeu-se que a história ensinada partindo das informações obtidas pela Internet, oscilava entre o factual, pois alguns dados eram enfatizados (nomes, datas e acontecimentos), e o curioso, ao se citar algumas contribuições culturais, considerando a culinária, as danças e os hábitos dos imigrantes. Desconsiderava-se, desta forma, que inúmeras questões poderiam ser problematizadas, inclusive por intermédio das mesmas informações coletadas pela pesquisa dos alunos.

A Internet funcionou da mesma forma que geralmente funciona o livro didático em sala de aula, isto é, os textos-informações foram encontrados e copiados pelos alunos e posteriormente recebidos sem

\footnotetext{
${ }^{4}$ Como dito, foram assistidas aulas de História durante 08 meses.
} 
questionamentos pelos professores como satisfatórios. A aprendizagem de novas informações, neste caso, se deu com pouca ou nenhuma associação com conceitos relevantes existentes na estrutura cognitiva, não havendo interação entre a nova informação e aquela já armazenada. Pode-se afirmar que a informação histórica não foi incorporada, acrescentada e relacionada à outra, portanto, não foi devidamente compreendida, e presume-se, será esquecida com rapidez.

Mesmo com as críticas que se pode fazer ao livro didático quanto à sua "ideologia", visão de mundo, silêncios, falhas, etc., há que convir que no cotidiano escolar, dificilmente o professor tem apoio didático-pedagógico a não ser pelo livro didático e o uso da Internet é exceção. Como diz Gatti Júnior, devido à formação do professor, à sua realidade profissional cada vez mais depauperada que lhe dificulta buscar outros materiais didáticos e cursos de atualização, assim como sua excessiva carga horária de trabalho - os professores observados perfazem 40 horas/aulas semanais - , suas leituras e pesquisas são restringidas, e os livros didáticos terminam por se tornar "os organizadores das atividades didático-pedagógicas exercidas pelos docentes para viabilizar os processos de ensino e de aprendizagem" (GATTI JR. 2004, p. 27), com amplo poder de interferir na maneira de como as disciplinas escolares se desenvolvem em sala de aula. Bittencourt (1997, p. 74) entende que, mesmo que o livro didático se caracterize pelo texto impositivo e diretivo, junto com exercícios prescritivos "existem formas diversas de uso nas quais a atuação do professor é fundamental". O que quer dizer que o livro didático, mesmo que tragam uma visão conservadora da história, não deve ser meramente descartado na prática do professor em sala de aula desde que seja avaliado em suas lacunas, compromissos políticos, adesão historiográfica, etc., ou seja, desde que (re)interpretado junto aos alunos.

Os professores afirmaram que o livro didático apresenta várias vantagens didático-pedagógicas, como: possibilidade de ampliar a leitura dos alunos; o uso das ilustrações e a sistematização dos conteúdos e o emprego do mesmo na preparação de suas aulas. Na ocasião em que os professores discutiram e produziram a grade curricular do município, 
revelou-se a concepção histórica destes no momento de optarem manter uma ordem cronológica dos acontecimentos históricos enfatizando acontecimentos políticos e na decisão de não organizarem os conteúdos por temas ou conceitos. A seleção de conteúdos realizada pelos professores para o currículo de história determina o tipo de livro didático que pretendiam adotar. Portanto, se os livros didáticos apresentam-se "questionáveis" porque "tradicionais" 5 . Na verdade, são coincidentes com o entendimento de história do professor que os selecionaram.

Os conteúdos históricos destes livros didáticos escolhidos pelos professores obedecem três princípios didático-pedagógicos: a ideia de que a aprendizagem ocorre mais facilmente do "próximo" para o "distante", do "concreto" para o "abstrato" e do "simples" para o "complexo". Para Penteado (1994, p. 28), "embora essa idéia seja procedente, é preciso examiná-la mais detidamente, a fim de não fazer dela um uso indevido ou inadequado". Às vezes o "distante", quando, por exemplo, aparece na TV, torna-se mais "próximo" do aluno do que a realidade do bairro onde vive. Ausubel entende de forma diferente a questão do "próximo" e do "distante", levando em conta a sua complexidade. Considera que a programação do conteúdo deve compreender uma "reconciliação integrativa", um delineamento de similaridades e diferenças entre ideias correlatas, e para isso, deve-se partir de conceitos mais gerais, que vão sendo progressivamente diferenciados em termos de especificidade, denominada "diferenciação progressiva" (CAIMI, 1999, p. 177).

Como o conhecimento histórico se pauta em conceitos e possuir conceitos é conceber coisas, seria importante em relação ao ensinoaprendizagem pensar o programa de conteúdos e o próprio desenvolvimento desses conteúdos pelo foco da diferenciação progressiva e reconciliação integrativa: trabalhar-se-ia conceitos partindo do conhecimento prévio dos alunos que envolvem a temporalidade e a

\footnotetext{
${ }^{5}$ A representação usual sobre o ensino tradicional de história encontra-se resumida, por exemplo, em Elza NADAI (1992/1993): memorização e a aula expositiva como métodos de ensino-aprendizagem; o conhecimento histórico como verdade obtida através da neutralidade e objetividade do historiador; tempo histórico associado à cronologia linearevolutiva; história nacional que buscava identificação com a civilização europeia e o destaque dado aos eventos políticos, à ação de indivíduos extraordinários (em geral, homens, brancos, ocidentais e cristãos) e à contribuição sem conflitos de brancos, negros e indígenas na formação e progresso da nação.
} 
localidade "mais próxima" deste, mas principalmente, os conceitos, as significações históricas que lhe são familiares, para só então relacionar esse conhecimento prévio com os conteúdos históricos curriculares. Portanto, seria contraproducente a grande quantidade de conteúdos e/ou de tópicos de assuntos observados na grade curricular do município para o $4^{\circ}$ ano e nos livros didáticos adotados, que englobam o estudo da história política, econômica e social do Brasil, desde a chegada dos portugueses até o regime republicano, destacando a ditadura e o processo de redemocratização. Diante de tantos conteúdos, questionam-se quais as noções, os conceitos de história que esses alunos levariam para o restante de sua vida escolar ou extraescolar ou relacionariam com suas próprias vivências/experiências.

Viu-se pela prática observada que, com ou sem a mediação do livro didático, é aquela história "tradicional", composta de datas, nomes e fatos a serem memorizados, que está sendo ensinada. Segundo TARDIF (2002), o saber docente (também chamado de "capital cultural-profissional") compõese de vários saberes: os saberes da formação profissional, transmitidos pelas instituições formadoras, que compreendem as ciências da educação e saberes pedagógicos; os saberes curriculares que complementam os saberes da formação profissional e apresenta conteúdos selecionados da cultura geral; os saberes experienciais que o professor adquire em seu trabalho cotidiano em seu meio de ação e, finalmente, os saberes disciplinares, que correspondem aos diversos campos do conhecimento como, por exemplo, história, matemática, ciências, etc. A partir do que se viu nesta pesquisa, os professores "generalistas" são imbuídos dos saberes das ciências da educação e dos saberes pedagógicos, ou mesmo dos saberes curriculares (saberes gerais da grade curricular do curso de pedagogia), mas quando se trata dos saberes disciplinares específicos, estes não são priorizados em sua formação inicial e contínua. Como já dito, isso não significa que os professores licenciados em história apresentem uma prática destituída de problemas: estes, supostamente, possuiriam o saber disciplinar referente à história, mas não aqueles imprescindíveis para didatizar este saber. Resta ao professor, aquele sem conhecimento 
aprofundado da disciplina histórica (ou aquele sem os conhecimentos didático-pedagógicos), lançar mão dos saberes experienciais, mesmo quando trabalha o livro didático, recorrendo à sua própria memória escolar sobre como deveria ser o ensino de história ou ao que apreendeu em diálogo com outros profissionais de maneira informal. Embora estes saberes experienciais sejam importantes para reinventar as práticas docentes, não fornecem condições suficientes para o professor refletir sobre sua prática, de modo a superar o que se entende como "tradicionalismo".

\section{A Apropriação dos Livros Didáticos e História pelos Alunos:}

Com a preocupação de investigar o que o aluno entende por história, como ele aufere as aulas de história e como se apropria do livro didático pela mediação do trabalho do professor, foi entregue um questionário aos alunos. Certamente, os resultados do questionário aplicado a um grupo pequeno de alunos não fornecem a dimensão real, mas aproximativa, sobre qual consciência histórica estariam desenvolvendo ${ }^{6}$.

No geral, $87 \%$ dos alunos disseram gostar das aulas de história e as justificativas foram as mais variadas, predominando a afirmação nas turmas de 1 e $2^{\circ}$ ano de que são "legais" ou "importantes". Como os alunos estão sendo questionados de forma que devem registrar por escrito uma opinião, existe a grande possibilidade de procurarem não desagradar o pesquisador, preferindo elogiar a disciplina histórica. Desta maneira, as respostas lacônicas podem indicar a necessidade de "satisfazer" o pesquisador e/ou pelo fato de nunca terem sido solicitados a avaliar sobre se gostavam ou não de história, e ainda pela dificuldade de explanar suas opiniões devido à fase em que se encontram no processo de aprendizagem.

Nas demais turmas, os alunos justificaram suas respostas de forma mais dissertativa e procuraram citar os conteúdos históricos que estavam estudando: "Sim, porque vejo as coisas que pode ter em Tarumã e também

\footnotetext{
6 Também se faz necessário considerar que os alunos pesquisados possuem a idade de 7 a 10 anos, não tendo ainda condições de explanar, dissertar e explicar as respostas com profundidade e complexidade. No entanto, mesmo diante destas limitações, algumas reflexões podem ser elaboradas a partir das respostas obtidas.
} 
eu aprendo muitas coisas nas aulas de história e as aulas são muito boas para a cabeça... elas são importantes para mim" (Paulo José, 30 ano); "Sim, porque fala sobre o Brasil que os portugueses vêm para o Brasil e acaba morando no Brasil. Sobre os escravos. Sobre os escravos que colhem café, etc." (Abner Lucas, $4^{\circ}$ ano). Alguns relacionaram de forma genérica a história com o estudo de acontecimentos passados: "Sim, porque eu aprendo mais o que aconteceu no passado" (Waldemar Junior, 40 ano); "Eu gosto, porque a gente aprende o que aconteceu antigamente" (Maurício, 50 ano); "Porque aprendo o que nunca soube... o que acontecia antes" (Thais Aparecida, 40 ano); "História é aquilo que aconteceu no passado, e que agora estamos estudando" (Maycon, $4^{\circ}$ ano). A história remeteria apenas ao passado, e na maioria das vezes, vista como passado-verdade: "É uma história verdadeira que aconteceu há vários anos atrás" (Érica, 40 ano). Assim, para o aluno a história é o que (realmente) aconteceu no passado, e seu estudo compreenderia os fatos sem relação com o presente e/ou com o contexto em que vivem. O passado é visto de forma cristalizada, como um bloco único, colocado em um tempo muito distante. Além disso, toda a "verdade histórica" estaria inscrito no livro didático, demonstrando também, uma visão "conteudista"7.

Esse modo de compreender a história como verdade e não como versões sobre o passado, não está relacionado somente à realidade investigada, pois, por exemplo, Peter Lee, em uma pesquisa realizada no contexto londrino conclui que para os alunos desse grau de aprendizagem "... o passado parece operar como fixo. Ou diz a verdade, ou não diz, e a verdade parece coincidir com o que é conhecido, um passado fixo" (LEE, 2003, p. 22). Segundo este autor, as crianças são ensinadas no meio familiar a sempre dizer a verdade e a tendência natural é que distingam "verdade" de "mentira", assim sendo, seria incongruente para elas pensar que o que dizem os professores e os livros didáticos - vistos como portadores legítimos da verdade e/ou do conhecimento -, poderia ser uma versão, uma interpretação da história e não "A História" (LEE, 2001; LEE,

\footnotetext{
7 Considera-se "conteudista" a organização curricular dos saberes históricos, pautada em tópicos postos de forma esquemática que corresponderiam aos acontecimentos históricos entendidos como "mais importantes", bem como a visão do sujeito de que quanto mais dados, mais se tem acesso a toda a história.
} 
2003). O próprio professor toma a postura de autoridade do conhecimento verdadeiro e da mesma forma lida com o livro didático, desenvolvendo no aluno esse tipo de perspectiva sobre a história.

Por outro lado, Barca (2001, p. 3), mesmo investigando os adolescentes, nos auxilia quanto ao papel do professor de história ressaltando que este não deveria extremar o "relativismo" da história, como se o passado fosse apenas uma questão de opinião pessoal ou "ponto de vista", mas precisaria fazer com que os alunos exercitassem um pensamento crítico. Argumenta a autora que, para alguns alunos, a história se equipara a uma invenção, e o livro didático a uma escrita ficcional. Interessante perceber que as respostas dos alunos do $4^{\circ}$ ano comprovam a tese de Barca: "História para mim é uma fábula que é escrita pelos autores" (Edinaldo, $4^{\circ}$ ano) e "Para mim é um conto de fada" (Paulo Henrique, 40 ano).

A seguir outras respostas sobre se gostam das aulas de história: "Sim, porque é gostoso ler as perguntas e depois ir pesquisar para tentar achar a resposta ou ler aqueles textos longos que também é uma delícia" (Wallace, 40 ano); "Sim gosto, porque ela ensina a gente ler e escrever para quando crescer ser alguém na vida" (Aline Roberta, 40 ano). Nota-se que para Wallace, a aula de história resume-se em procurar respostas nos textos, o que pressupõe o questionário como atividade de "pesquisa". Um questionário que demanda copiar a resposta seguindo literalmente o texto, e não um questionário que faria o aluno refletir e construir um texto próprio. Já Aline Roberta, acompanha o senso comum de que o estudo, de qualquer disciplina, estaria vinculado à ascensão socioeconômica e deste modo, a história ensinada é por ela vista de forma independente de seu conteúdo específico, isto é, seria mais uma disciplina que faz parte das exigências da escola para "ser alguém na vida".

Os alunos que não gostam da disciplina de história utilizaram em suas justificativas as palavras "chata" e "complicada". As respostas desta questão estão relacionadas com as respostas da questão "Você gosta do livro utilizado nas aulas de história?", mesmo considerando que apenas 9\% disseram não gostar do livro didático: "Eu não gosto de história porque o texto é grande" (Kauê, 30 ano); "Não porque os textos são muito compridos 
e eu não entendo nada deles" (Thays, 40 ano); "Não, porque os textos são muito longos e a maioria dos textos falam dos escravos que estavam apanhando" (Jéssica, $4^{\circ}$ ano). A história, seu ensino e o livro didático são vistos de forma indissociáveis, portanto, gostar, entender, valorizar esta disciplina tem correspondência direta com a capacidade de apreender a narrativa do livro didático. Quanto às respostas à questão "Para você, o que é história?", novamente nota-se que para os alunos, a história se restringiria a um texto escrito (a do livro didático), ou melhor, a um texto que descreveria todos os acontecimentos passados: "História é para mim um texto que fala sobre o Brasil" (Karoana, 40 ano); "Para mim história é um texto que fala história do nosso país" (Ricelli, 40 ano); "Porque os textos são muitos legais" (Anderson, 40 ano).

Transparece nas falas dos alunos que o professor sustenta seu trabalho didático-pedagógico atendo-se ao que está disposto no livro didático, o que reforçaria a identificação deste com o que seria A História: "Porque sem o livro não tem graça, porque a professora ia contar as histórias e nós não poderíamos acompanhar e nem ver os desenhos" (Thais, 40 ano); "Porque com o livro as aulas ficam mais fáceis" (Jéssica, 40 ano); "Porque sem ele eu quase não entenderia as aulas. Porque é um livro informativo, com assunto de outras épocas" (Fernanda, $4^{\circ}$ ano).

Quanto à questão "Você entende os textos e as atividades do livro de história", 56\% dos alunos responderam que sim, 10\% responderam que não, $26 \%$ disseram às vezes e $8 \%$ só o entendem com o auxílio do professor. Tal questão revelou dois aspectos importantes, primeiro que a linguagem dos livros didáticos nem sempre é apropriada à faixa etária e/ou de capacidade de apreensão dos alunos, pois $44 \%$ dos alunos não conseguem fazer sozinhos as atividades. Os alunos apresentam certa dificuldade para interpretar os enunciados das questões, o que de acordo com os professores não ocorre só com o livro didático de história, mas também com os livros didáticos das demais disciplinas. No entanto, se o livro didático é visto como portador da história, como pilar das atividades pedagógicas, e este não estaria sendo compreendido pela maioria, não fica difícil presumir uma história ensinada/apreendida de forma não crítica. 
Provavelmente, quando os alunos dizem gostar do livro didático (91\% destes), que o que estaria sendo aproveitado do livro didático seria muito mais o rol de imagens do que o conteúdo histórico em si. Sem outros recursos didáticos, o que ainda sustenta a motivação e/ou o interesse do aluno, bem como o tema e a metodologia da aula de história seria o livro didático, mesmo quando mal compreendido em seu conteúdo intelectivo. Talvez isso aconteça simplesmente por constituírem na (única) maneira de o aluno não precisar copiar textos da lousa, mesmo que alguns alunos achem que "os textos [do livro didático] são grandes demais para ler e para copiar", mas as justificativas para se interessar pelo livro didático estão, na maioria, centralizadas na questão das imagens. Estas facilitariam o entendimento sobre o conteúdo que estaria sendo ensinado e serviriam como meio de amenizar o caráter desinteressante e complexo da disciplina histórica escolar, ao desassociar história de texto escrito.

Cada vez mais trabalhadas, coloridas e chamativas, as editoras parecem dar mais atenção à iconografia do que com os conteúdos e/ou conceitos históricos. Segundo Bittencourt (1997 p. 73), a apropriação dos livros didáticos pelos professores e pelos alunos é variada, e apesar de suas deficiências e lacunas, as imagens podem ser transformadas em "instrumento de trabalho mias eficiente e adequado às necessidades do ensino autônomo" A autora conclui baseada nas reflexões de Lavisse, que a inclusão de ilustrações no livro didático ainda serviria a objetivos pedagógicos "tradicionais". Pelo que consta nas respostas dos sujeitos da presente pesquisa, as imagens do livro didático não estariam sendo empregadas pelo professor de modo a produzir a construção de conceitos históricos, servindo ao simples propósito de ilustração, complemento, confirmação do texto e ajuda na memorização dos conteúdos. Percebe-se assim, que as ilustrações não são trabalhadas como fonte didático-histórica, e sim para comprovar a veracidade dos conteúdos históricos.

Considerando as respostas dos alunos, a aversão à disciplina de história pode ser explicada de várias formas, pelo fato destes: pensarem a história como disciplina escolar repleta de pontos a serem memorizados; terem como atividade um tipo de questionário que induz a cópia do livro didático ou de textos on lines e por não conseguirem ler o livro didático ou 
textos da Internet de forma interpretativa. Sobretudo, o ensino de história, mesmo para aqueles alunos que dizem gostar desta disciplina escolar, não apresenta um sentido relevante para suas vivências, já que não se desenvolve uma aprendizagem significativa, daí que o passado é visto de forma estática e assim, descarta-se a ideia da atuação e do pensamento dos sujeitos no processo histórico.

Se existe uma tendência acentuada de o professor fornecer aos alunos uma história "tradicional", da mesma forma os alunos têm a propensão em entender a história de modo "tradicional", ainda que isso não seja uma regra. Como a apropriação do livro didático pelo professor não seria unívoca, compreendendo várias re(significações), também assim acontece em relação à apropriação dos alunos quanto às aulas do professor sob mediação do livro didático. Por isso, algumas respostas, de certa forma, diferem da perspectiva "tradicional" da história: "História é tudo aquilo que você aprende na escola, em casa, na loja de nossos pais" (Andreza, 40 ano). Este depoimento exemplifica a compreensão de que a história não se aprende/ensina apenas pelos meios formais como a escola, o que confere com o pensamento de Thais Fonseca: o cotidiano escolar sofre múltiplas relações com outras instâncias de circulação e difusão de saberes (FONSECA, 2003, p. 08). Portanto, valores, conceitos e noções históricas veiculadas através destas instâncias (mídia, família, igreja, etc.) interferem, mesmo que parcialmente, na maneira que o aluno (re)elabora sua consciência histórica.

Ao invés de pensar a história "como tudo aquilo do passado que aconteceu", Wagner considera, ainda que não desvinculado da ideia da história como verdade, que os acontecimentos históricos são produzidos no cotidiano: "É o que aconteceu no dia a dia de um município e também antes de eu nascer, é muito bom ter a matéria de história" (Wagner, 40 ano). Também para outra aluna, a história não se restringiria às informações sobre os acontecimentos passados, mas estaria relacionada com a vida cotidiana, seja no passado, seja no presente: "História para mim é contar um pouco da vida de cada um, contar onde mora, como vivem" (Renata, 40 ano). Enquanto que Maxell concebe a história como produção de uma 
narrativa, em que não basta "ocorrer" os acontecimentos históricos para haver o passado, mas haveria que "torná-los" história: "História é uma coisa que acontece e com o passar do tempo vira história, como a do Brasil" (Maxell, 40 ano).

As respostas mais elaboradas vieram dos alunos do $4^{\circ}$ ano como visto acima, e deve-se lembrar que as respostas mais aprimoradas constituem exceções, e pelo que se pôde averiguar por meio da observação no espaço escolar e pelos questionários, a maioria dos alunos demonstrou que não Ihes foi oportunizada uma aprendizagem significativa sobre o próprio conceito de história, nem por intermédio dos professores (que encontram dificuldades em promover de forma satisfatória o ensino/aprendizagem), e nem pela mediação do livro didático adotado pela escola (por não trazerem uma perspectiva historiográfica inovadora e por não serem aproveitados pelos professores como material que pode ou deve ser criticado). Grande parte dos alunos não conseguiu ver (o que muitos professores também não conseguiram) como nos quatro últimos depoimentos que: os saberes históricos não estão somente sob a "guarda" do professor e do livro didático, mas podem ser encontrados em outras esferas da vida; a história não se vincula apenas aos grandes acontecimentos, mas também aos acontecimentos do cotidiano; o passado transforma-se em história(s) quando narrado e interpretado; o passado tem sentido quando posto em correspondência com a "vida de cada um".

\section{Considerações finais}

Considera-se, pela pesquisa realizada, que o professor "generalista" tende a dar aulas de história e utilizar o livro didático referente a esta disciplina escolar de forma problemática, devido à sua formação profissional inicial e contínua que desconsidera a importância dos saberes disciplinares, ou seja, dos saberes que caracterizam as disciplinas específicas. Também se observou que os alunos, devido à mencionada formação deficitária do professor, apresentam dificuldades de compreender conceitos históricos, aliás, de compreender o próprio conceito de história. Assim, o descrédito 
em relação à disciplina histórica por parte dos alunos está relacionado ao fato de que estes, em geral, não conseguiram dar uma razão, um sentido para o seu estudo.

A vertente da história "tradicional" e /ou "conteudista", embora criticada teoricamente, mostrou-se recorrente quando na prática em sala de aula. Entre mudanças e permanências, o ensino de história estaria, pelo menos no que diz respeito ao grupo pesquisado, inclinando-se mais para as permanências, por mais que professores e alunos sejam sujeitos ativos capazes de reinventar suas práticas e representações (CHERVEL, 1990). No entanto, se existe um professor "tradicional", isso se deve mais às condições de sua formação e de trabalho do que à sua vontade ou disposição em inovar.

A desconstrução de discursos e imagens do livro didático cria probabilidades de discussão e de alargamento do campo de visão do aluno e do próprio professor os quais poderão atuar como pesquisadores na tarefa de tratar o livro didático como uma fonte documental, representativo de uma determinada visão de mundo e de história, passível de ser (re)interpretada em sala de aula. Para que isso possa acontecer, urge apresentar tanto aos professores como aos responsáveis pelos cursos de formação de professores, a necessidade de se valorizar tanto os saberes disciplinares (específicos) como os saberes pedagógicos, para que, no caso do ensino de história, os professores adquiram através de seus cursos de formação, condições para poder fazer com que seus alunos construam o conhecimento histórico pela aprendizagem significativa.

Os avanços tecnológicos (principalmente dos meios de comunicação), a mudança no mundo do trabalho, a cultura do imediatismo e a fragmentação do conhecimento, característicos da sociedade contemporânea indicam a importância de se construir pelo ensino de história, um entendimento em relação ao passado para que o sujeito não se perca diante das transformações do mundo e de si mesmo (RÜSEN, 2001, p. 60). Para além da História atraente, por vezes curiosa e exótica, geralmente apresentada nos materiais midiáticos, os saberes históricos, quando construídos em sala de aula a partir dos pré-conhecimentos dos 
alunos, bem como da crítica e da problematização, possibilitam ultrapassar a percepção da realidade imediata. Isso significa fazer com que este aluno, ao se compreender como ser situado em uma escala mais ampla do tempo, possa pensar-se como sujeito, sobre quem é, no que se tornou e no que possa vir a ser (e fazer).

\section{Referências}

ANDRÉ, M. E. D. A. de. Etnografia da Prática Escolar. Campinas: Papirus, 1995.

BARCA, I. Concepções de adolescentes sobre múltiplas explicações em História. In BARCA, I. (Org.). Perspectivas em educação histórica. Portugal: Centro de Estudos em Educação e Psicologia; Universidade do Minho, 2001.

BITTENCOURT, C. Livros didáticos entre textos e imagens. In

BITTENCOURT, C. (Org.) O saber histórico na sala de aula. São Paulo: Contexto, 1997, p.72. 2004. . Ensino de História: Fundamentos e métodos. São Paulo: Cortez,

BOURDIEU, P. Compreender. In BOURDIEU, P. (Coord.) A miséria do mundo. Petrópolis, RJ: Vozes, 1997.

CAIMI, F. E. O livro didático: algumas questões. In DIEHL, A. A. (Org.). O livro didático e o currículo de história em transição. Passo Fundo: EDIUPF, 1999.

CHERVEL, A. História das disciplinas escolares: reflexões sobre um campo de pesquisa. Teoria e Educação, Porto Alegre, n. 2, p.177-229, 1990.

FONSECA, T. N. História e Ensino de História. Belo Horizonte: Autêntica, 2003.

GATTI JÚNIOR, D. A escrita escolar da História: livro didático e ensino no Brasil (1970-1990). Bauru, SP: EDUSC, 2004.

LEE, P. "Nós fabricamos carros e eles tinham que andar a pé": compreensão das pessoas do passado. In BARCA, I. (Org.). Educação histórica e museus. Portugal: Centro de Investigação em Educação; Instituto de Educação e Psicologia; Universidade do Minho, 2003, p. 22.

LEE, P. Progressão da compreensão dos alunos em História. In BARCA, I. (Org.). Perspectivas em educação histórica. Portugal: Centro de Estudos em 
Educação e Psicologia; Universidade do Minho, 2001.

NADAI, E. O ensino de história no Brasil: trajetória e perspectivas. Revista Brasileira de História. Memória, História, Historiografia. Dossiê ensino de história. v. 13, n. 25/26, pp. 143-162, set. 92/ago. 93.

PENTEADO, H. D. Metodologia do ensino de história e geografia. São Paulo: Cortez, 1994.

RÜSEN, J. Razão histórica: teoria da História: os fundamentos da ciência histórica. Trad. Estevão de Rezende Martins. Brasília: Editora Universidade de Brasília, 2001.

TARDIF, M. Saberes docentes e formação profissional. 4 ed., Petrópolis, RJ: Vozes, 2002. 